\title{
ON THE EPIDEMIOLOGY OF PLAGUE'.
}

\author{
By J. ASHBURTON THOMPSON, M.D., D.P.H., \\ President of the Board of Health and Chief Medical Officer of \\ the Government of New South Wales.
}

\section{Introduction.}

1. Discordant views on the aetiology of plague, and their causes.

IT is now twelve years since it first became possible to study plague by modern methods, and yet no conclusion on its aetiology has been reached which has met with general acceptance. Two causes, as it seems to me, have chiefly contributed to this disappointment. One consists in the appeal which has been persistently made to bacteriology for lights which in fact are not in its power to shed; the other is neglect of the epidemiological method, or at least failure to apply it effectively. In consequence, a field has been occupied by the bacteriologist which could not be profitably laboured by him. The epidemiologist has not seriously disputed this usurpation of his domain, and for his apparent apathy he has not been without excuses of some weight.

2. Limitation of previous epidemiological investigation into plague.

Plague has almost always appeared in countries inhabited by races foreign to the observer in their language and modes of thought, who were of little instruction, of an education limited to ancient and immutable conventions, and who lived for the most part under conditions which unavoidably obscured the phenomena. It has thus often been impossible to acquire that exact and complete knowledge of all the circumstances under which the infection had been received by each person attacked, which is the foundation of all investigations into the aetiology of disease by the epidemiological method.

1 MS. received 30. v. 1906 . $E d$.

Journ. of Hyg. vi 
The conditions adverted to notoriously existed at Hongkong, and in India ; they made themselves more or less completely felt in New Caledonia, in Madagascar, in Mauritius, in Egypt, and in parts at least of South America ; and they obtained effectively in South Africa where, although the ruling population is English, the burden of disease fell on the natives and on immigrants from the East. But plague has visited some places where the conditions were more favourable to investigation, and from them (as well as from those just mentioned by name) much information of clinical, pathological, and administrative value has been forthcoming; but there the principles and uses of the epidemiological method seem to have been greatly overlooked.

\section{Relative absence of such limitation at Sydney.}

At Sydney the conditions happened to be much more favourable to its employment. The invaded population numbered about half-a-million. It was not merely wholly white, of English extraction and speech, and fully civilised, but intelligent, instructed, and orderly, accustomed to direction and amenable to it. Management of the outbreaks rested solely with the central Department of Public Health, which had not merely wide statutory powers, but in unforeseen contingencies had the practically unlimited authority which the Executive Government occasionally conferred upon it.

\section{The subject of investigation.}

I have not drawn attention to these circumstances unnecessarily. They constitute the condition precedent to success in any epidemiological investigation to which, as is the case with plague, co-operation of the people themselves is requisite. So advantageous were they, indeed, that I am tempted to refer to our observations as "normal observations," and to our results as "normal results." The subject of enquiry, it is well to say, was not plague in general, but epidemic plague in the two clinical forms which at present are commonly distinguished as the bubonic and the septicaemic. From them the uncommon third clinical form known as primary plague pneumonia differs so remarkably in its mode of spread, which is simply by direct communication from the sick, that it may be left aside.

\section{Conclusions on the aetiology of plague reached at Sydney.}

With the great mass of data which the epidemiological method placed at command, and which has been fully set forth in a series of 
published official reports, I have framed the following conclusions by induction :-

(a) Plague owes nothing of its epidemic form to communication with the sick.

(b) Plague in the rat is a necessary factor in epidemic plague.

(c) A living intermediary is necessary to communicate the infection from rat to man.

(d) That intermediary must be the flea in one or more of its many species.

\section{Phenomena of Epidemic Plague.}

\section{The infection is not diffused by communication with the sick.}

(a) Direct communication. In 1900, when plague first made its appearance in this quarter of the world and at Sydney, the disease was generally thought to be maintained and diffused by communication with the sick.

Condon (1900) deplores the ignorance of the origin and modes of spread of plague which existed (p. 12). While escape of persons employed in hospitals was taken to show "that the germs produced in the bodies of the sick were but little infectious to healthy persons under ordinary circumstances" (p. 72), it was, on the other hand, stated that "the microbe is capable of thriving and multiplying outside the animal body...." so that "the germs may be conveyed by persons who are themselves insusceptible to plague, and having grown and multiplied on suitable media...may infect large numbers of people..." (p. 69). And the general trend of Hankin's observations was said to indicate that the chief source of infection would more probably be found in "the recently passed excreta of men and of animals suffering from the disease" than in a saprophytic growth in the soil (p. 111). At the date mentioned exact evidence on the communicability of plague was not possessed.

At the present date official opinion in India is that communication with the sick is a means of maintenance of the disease, and must be borne in mind in framing preventive measures. In a resolution of the Government of India, dated Calcutta, 17th January, 1906, designed to place on record in concise form the results of practical experience acquired in the management of plague during the preceding five years for the guidance of Presidency and Local Governments, the following sentences were included : "...the inspection of travellers by railway, road, and steamships, is often successful in averting or delaying the spread of plague..." (par. 6). "The example of prisons proves that quarantine may be relied upon to prevent the spread of plague by human beings..." (par. 7). "The removal of the sick to hospital...is instrumental, however, in delaying the spread of the disease..." (par. 8). 
The first outbreak in Sydney consisted in 303 cases, and the requisite particulars were learned in 289 of them. Those 289 persons had lived in 276 dwellings ; 266 of the dwellings had harboured but a single case apiece. After an interval of 15 months, during which no plague had been seen either in man or in animals, the second outbreak began. It consisted in 139 cases, which were found in 124 dwellings (including one ship long in port); 115 of those dwellings harboured but a single case apiece. Subsequent experience has been precisely the same. The patients were very promptly removed to hospital after notification, no doubt, but in the vast majority of cases which came under treatment notification was delayed until the third day of illness, or later still; additional to them were 51 persons who died at home at, or before, the hour of notification. All those persons, then, had ample opportunity of communicating their disease to their housemates but, as appears from almost all the dwellings having harboured only one case, they did not do so. Further, many of those persons received the infection at the centre of the City which was the original point of invasion, and retired to their dwellings as soon as they began to feel ill. Those dwellings were situated in large proportion in the suburbs, from two to three miles up to about ten miles away from the centre; and about a dozen persons reached places some hundreds of miles away, where they passed through their illness under circumstances which did not permit of isolation from the rest of the family nor, perhaps, from their neighbours. In all of the very distant places, and in a very large proportion of the suburban places, no plague, either in man or in animals, was afterwards seen. Non-communication was the rule, then. What at first appeared to be secondary cases did occur occasionally; but I shall show that they resulted from exposure to a common source of infection, not from communication with the sick.

Even in India it has turned out to be possible to examine the question of communicability in a similar way; and as soon as it was so examined similar evidence was obtained. Pearse, 1904, stated the figures for three of the Districts of the city. In District I, 1521 cases occurred ; 1002 huts furnished only 1173 cases, and 287 pucka buildings only 316 cases (and 32 cases were undistributed). In District II, there were 2049 cases; 1023 huts furnished only 1222 cases, and 642 other buildings 827 cases. In District III, there were 728 cases; 539 huts yielded but 582 cases, and 127 pucka buildings only 137 cases (and 9 cases were undistributed). Unfortunately notification was far from complete, though improved; however, Dr Pearse thought that this evidence weighed against maintenance by communication with the sick, against indirect communication by fomites, and against persistence of the infection on premises. 
(b) Indirect communication. Dissemination of the infection by means of articles which had become infected in plague-houses so as to contribute importantly to production of an epidemic, if at all possible, could take place only if those who suffered commonly pawned or sold their household goods during illness. As a matter of fact, no such diffusion of articles took place. Distress, consequent on illness and loss of work, had not time to make itself felt before the houses fell into the hands of the disinfecting staff. But were the infection commonly capable of being spread indirectly by infected articles no such clear answer as that given to the preceding question could have been made. We have no ground for suspecting that the infection of plague can be spread by clothing, bedding, or other articles of household use.

Can articles which were not infective within houses become so as a consequence of mere removal outside the houses? Accounts are forthcoming from India of transmission of this infection with clothes, or by persons who were not themselves suffering. The surrounding circumstances in which such cases were observed have not been described in the requisite detail; however, had sufficient experimental evidence that fleas could communicate plague been already adduced, then it would be easy to understand how articles which appeared to be not infective within houses might become so after issuing from them. For during transport the fleas would be starved, and they would seize the first opportunity of taking blood (Tidswell, 1902, p. 73 ; Gauthier and Raybaud (1903)). It should be noted with reference to those Indian accounts that our people, having been respectable artisans, etc., for the most part, were not infested with vermin as the poorer natives of India generally are.

The evidence, then, collected under the usual conditions of civilised life in 1900 and in 1902, suffice to show that neither direct nor indirect communication with the sick is a factor in the causation of epidemics, and this fundamentally important judgment has been fortified by all the experience of subsequent years. It carries with it the corollary that the infection spread in epidemic form by means which were (a) external to man, and (b) independent of his agency.

\section{The infection is associated in some way with locality.}

The disease claimed many victims, although it did not spread from person to person. The infected must have shared something, therefore. We discovered what this was as soon as scrutiny of dwellings in relation to infection was exchanged for scrutiny of workplaces. Already in 1900, 17 groups of cases had been noted which consisted of from two to four persons in each, the total number concerned having been 43 persons, who occupied 43 separate and scattered dwellings. There 
was no other bond between the components of each of these groups than resort to the same workplace. In subsequent years we met with other groups of which the component persons were connected solely by resort to the same workplace, the same hotel, or (in one case) even to the same theatre. Under our "normal conditions" we were able to establish the important facts concerning each of them fully, and quite certainly.

\section{Incidence of the disease on households is erratic.}

Yet infectiveness of the locality did not ensure the infection of persons present in it. On the one hand non-communication of the disease from the sick prepare us to meet with but single cases in dwellings, and that was the rule; on the other hand connection of the infection with locality seemed to make it almost certain that secondary cases must be met with in buildings which were places of infection for primary cases. Accordingly, secondary cases often occurred in buildings which were infective; nevertheless much more commonly only one person suffered out of several who were equally exposed, and who (since man's natural resistance to plague is very slight) were all equally susceptible. I wish here to direct attention more especially to the very commonly observed escape of all but one member of the exposed group. It has from the beginning caused me to suppose that a chain of circumstances which is rarely complete in all its links must be necessary to the infection of man (Ashburton Thompson, 1900, p. 36).

\section{Extension of local infection by contiguity.}

The infection always first made its appearance at some one spot; never at more than one. From that spot it extended continuously, and its progress could be watched. The limits of the area on which it was present could be and were ascertained, time after time; and although, in the nature of the case, they could not be sharply defined, it was always possible to say where plague-free areas existed beyond them. This way of spreading I distinguish as " extension by contiguity."

\section{Extension of local infection per saltum.}

While the infection was apparently present only at the point of invasion or central focus, it often made appearance quite suddenly at some distant point, and there created a new focus. The intervening 
country although covered with houses remained unaffected either permanently, or until some very much later date, when it became infected by contiguity, either from the central focus or from the secondary focus itself. It appeared that the infection could be transported safely, be planted afar, and could there take effect. In that there is nothing novel, for the same happens with several communicable diseases. It becomes remarkable and important when it is remembered that, in accordance with our fundamental observation, the infection of plague is not maintained or diffused by communication with the sick. This way of spreading I distinguish as "extension per saltum."

\section{Incidence of the infection on houses is erratic.}

From the beginning it was observed as well in urban as in suburban districts that infection of a house betokened no particular danger to the adjoining houses. But it did betoken danger to houses in its neighbourhood. It was remarkable that the apparently imminent danger was realised but rarely, while the apparently remote danger was almost invariably realised sooner or later.

\section{Sub-epidemics.}

For convenience of description outbreaks which result from extension per saltum may be called "sub-epidemics." In reality they have their own independent status, and are as much entitled to be named "epidemics" as is the outbreak at the primary focus, or point of invasion. The sole difference between the primary and such secondary outbreaks is this. Whereas the infection was carried from great distances oversea to the point of primary invasion, it was carried from that point to the secondary foci over the shorter distances which separated them from it. The numerous secondary outbreaks which we have witnessed were not the less independent that they were isolated by but a mile-wide ring of plague-free houses, nor the more independent that they occurred (as we have seen) 70 miles or 300 miles away from the point of primary invasion; nor were those distant sub-epidemics less independent than was that at the point of primary invasion itself, though the latter may have stood thousands of miles from the source of its infection. A consequence of great value in the epidemiological investigation of plague flows from this. It is that sub-epidemics can be compared with the primary epidemic, and with each other. Even in a single city checks on observed data thus become available; corrobo- 
ration, also, on points which stand the test of such comparison. It will appear presently, I believe, that the mode of diffusion of plague is always one and the same, and that distance is an incidental accompaniment, without real significance, and of very little practical importance.

\section{Infected areas.}

It is customary to speak of "infected areas" and the phrase is convenient for administrative use. But in epidemiological terminology it is inexact. Our "normal results" have shown that the infection of man is almost always contingent on his presence within buildings of some sort. Infectiveness of areas is entirely conditioned by the infectiveness of some of the buildings which stand upon them.

\section{Non-persistence of the infection in localities.}

The infection is but casually connected with localities; it does not inhere in them.

(a) Districts. The after history of a good many areas on which sub-epidemics have occurred, traced during terms of years from six downwards, has shown that the most ordinary processes of scavenging and cleansing as applied to accumulations of rubbish, dilapidated buildings, backyards, and basements, has sufficed to banish the infection. Any such area might of course become reinfected per saltum from any other distant area with which it remained in unguarded communication; but in the many instances $I$ now have in mind this happens not to have occurred, with a single conspicuous exception. This consisted in the central area itself. One small part of our extensive wharf-lines has always been the point of primary invasion; it does not measure much more than a mile in length. I shall be able to show at the proper time that this is one of those exceptions which prove the rule. Our normal observation is secure; simple scavenging of rubbish and filth, without any general disinfection or other special method, gets rid of the infection once for all.

(b) Houses. 221 houses were adjudged in 1900 to have been the places at which many of the 303 cases of that outbreak had received their infection; they were infected houses and the cases they yielded were "indigenous" to them. In 1902 the disease revisited the area on which those 221 infected houses stood; and then 86 houses were adjudged to have been places at which 113 persons received their infection. But, in the second epidemic, large areas which had carried places of infection in 
the first epidemic were entirely spared. No fewer than 215 of the 221 plague-houses of 1900 escaped in 1902 ; and as regards the six houses which were revisited in the latter year, only four of them could be regarded as having been places of infection in both years, the other two having merely harboured persons who were adjudged to have received the infection elsewhere. Since the infection recurred in the second outbreak on the same area it was manifestly probable that a few houses would be invaded a second time; and that, I think, is the proper view to take of the very small residuum of four houses out of 221 which were places of infection in both years. This exact statement has been supported by the result of all further " normal" observation. As the infection does not inhere in localities, so neither does it inhere in buildings; but to both it may be re-imported.

The suggestion that plague is an infection of locality has authority. The Chinese have always (as far as we know) held the opinion that plague emanated from the soil, and probably they deduced it from having observed that what they took to be the same disease as killed animals which live near to or in the soil afterwards attacked man. They elaborated it into the fantastic theory on which plague was thought by them to attack many kinds of animals in a succession regulated by the height at which they carry their heads above the ground, so that man suffered last. This belief, that the infection of plague resides in the soil, has been entertained and advocated by Creighton, who adopted it in his History of Epidemics in Britain, and reaffirmed it (1905) after having paid a visit of investigation to India. He thought the infection rose to the interior of dwellings with the ground-air, and was commonly taken by man with the breath. The belief "that plague is essentially a disease of locality" and that houses are infective in themselves was according to the Indian Plague Commission (1901) general in India.

Our "normal" observations have furnished no support to this view. As it appears to me, the infection must exist under one of three forms:-(a) as an infection of the animal body, be it vertebrate or invertebrate; $(b)$ as a discharge from the animal body on inanimate objects, to which I have allocated the phrase "deposited infection"; and (c) as a saprophytic growth. But I have just given some reasons, and before concluding I shall adduce others, for thinking that it does not exist in efficient form (efficient, that is to say, $q u \hat{a}$ epidemic prevalences) outside the animal body.

\section{Outline of the epidemic form.}

The general form of our epidemics, and of all epidemics (except those of primary plague-pneumonia) concerning which the details are sufficiently known, is $(a)$ commencement in a very few cases which are separated from each other by considerable intervals of time, (b) a more rapid succession of cases, and (c) a conclusion resembling the com- 
mencement, but, as a rule, not so long drawn out. This outline is clearly seen when the number of cases is considerable but it is lost when the number is small, and the character of the outbreak then seems to be mere irregularity of the order of succession; the intervals between the cases being often many times as long as the incubation period of the disease.

The latter point is conveniently illustrated by our fourth outbreak, which consisted in 12 cases only. I give the intervals after premising that the incubation period of plague is most commonly 3 days or less, and perhaps may be said never to exceed 5 days. The date of attack in the first case of 1904 was 9 th of March; the successive intervals at which the remainder occurred were $32,10,12,3,13,17,6,20$, 41,38 and 3 days (but the last two cases occurred in the same house).

\section{Epidemic plague is associated with epizoötic plague.}

Our investigation of the 12 cases in which the small outbreak of 1904 consisted was pushed to the last extremity. It will be well worth while to examine the places of infection under their groupaspect at this point, for we are on the brink of an important transition. The number of infective premises was nine; seven of them, of which two furnished two cases each, were grouped by standing at or near the point of invasion; the eighth and ninth (which latter also furnished two cases) stood about 6 and about 10 miles away from it in opposite directions, and were infected from it per saltum. Now, we bave learned already that infectiveness of districts is conditioned by the infectiveness of particular premises which stand within them; and when the relationship of the seven premises which, in the district sense were grouped was examined more closely, it appeared that in reality they did not stand near each other, but in almost every case were rather widely separatedseparated, that is to say, by two or three blocks, by a quarter of a mile of city property, or even by longer distances. Something they shared, for they were all infective; but that something can have had no essential or necessary connection with the area on which they stood. We found the circumstance which was common to all of them in the presence of plague-rats. That, and that alone, distinguished the district in which seven of them stood, and the distant neighbourhoods in which the eighth and ninth stood, from the rest of the metropolitan area. I have mentioned these results in connection with 1904 partly because the small number of cases makes that outbreak a convenient example, and partly because in that year we established the distinction mentioned, namely, 
the presence of plague-rats in every case without exception; but it had also been observed by us in previous years.

If all the "normal results" which I have described separately be now considered together I think it will be conceded that nothing can co-ordinate them, and reconcile the apparently contradictory features of some of them, except the assumption that the infection of plague exists in, and is disseminated with, the bodies of some species of lower animal which is free to wander. Thus the centre of interest passes for the present from man, to the only animal which at once lives in close association with him and is conspicuously subject to plague.

\section{Phenomena of Epizoötic Plague.}

1. Need to watch the rat closely and continuously.

The association between plague in man and in rat which has now been very frequently observed in many different parts of the world tempts the inference that man takes plague from the rat; and it has been very generally drawn. However, on reflection it will appear that no good ground of inference has thus been disclosed, and that in reality only a coincidence has been noted which collateral circumstances have shown to be worth investigation-the scent, not the quarry. But systematic investigation has rarely been accorded to it. As a rule the observed points consist solely in plague in $(a)$ man, and $(b)$ concurrent plague in the rats in his neighbourhood. Nothing is known, or at least nothing has been intelligibly recorded, of the rats over the whole of any town, in the parts where plague is not as well as those in which it is. Hence the question of causality has been left open. A suggestion that both may have taken the infection from some common source remains plausible; and it is by no means disposed of by showing (as has been shown with that intention) that persons who live away from the ratinfested neighbourhood only take the disease if they resort to it, or only after diseased rats have been observed in the neighbourhood of their dwellings. In order to elucidate it it is necessary that the rat should be watched all the year round, while plague is present and when it is absent ; and in reporting results it is further necessary that the duration, extent, and means of search, as well as the way in which infection with plague was ascertained, should be carefully described. This has not yet been done in India; and it is precisely in India that many experiences 
have been recorded from which, it is said, it has been learned that epidemic plague can occur out of association with rat-plague. I am going to show that although plague-rats do in India and in some other countries often come out to die in the open, and thus to some extent offer themselves for inspection, systematic detection of rat-plague is in reality a difficult business.

The methods employed at Sydney fell under two heads : rat-destruction and rat-intelligence. Rat-destruction was secured by payment of a capitation fee for carcases to the public ; the carcases were delivered at furnaces where they were recorded and burnt. The furnaces were in charge of intelligent men of the temporary staff, who were directed to report any general information they might pick up. None of the rats received there were examined in the laboratories because good information as to the places at which they had been taken could not be got from the persons who usually delivered them. Rat-intelligence was got through a special staff, which consisted at first of the best men we could find ; but by a careful process of weeding out a trustworthy corps was gradually got together, most of whom at the present date have been continuously employed since the beginning of the second outbreak (1901-2). The provenance of all rats taken by this staff was accurately known. The catch of the previous night was delivered at the laboratories with the address at which each animal had been taken attached to its carcase ; the address was entered in the rat-register; the carcases with their attached addresses were handed to the staff of laboratory assistants, and were examined by them under supervision of the Director. The results were then entered in the register. As soon as plague was detected in a carcase which came from a house not previously known to carry the infection, the address was communicated to the medical staff, and was spotted on the map; the sanitary staff was instructed to repair to the premises with their scavengers and cleansers; their operations began with the infected premises and the adjoining premises on each side of them, but were extended to the whole block. Every rat taken during these cleansing operations, as well as the particular premises in the block on which it had been found, was also examined and was recorded at the laboratories. The general sanitary state of the block was reported in detail by the Sanitary Inspectors (all of whom were trained and certificated); they drew attention to matters of special importance, and these were further examined by a Staff Medical Officer. This method has been followed continuously since 1st April, 1902, and is effective at this moment. In plague-free times there has been no need for it in some of its details ; but examination of rats by means of the intelligence-staff has never been intermitted. Their work has not covered the whole of the 256 square miles of the metropolitan area, any more than it has extended to the whole of the 311,000 square miles which the State comprises. Experience has taught us that when the infection reappears it will be first found at the short length of wharf-line already mentioned; and to a wharf-line of about four miles in length which includes that portion, and to the immediately adjacent streets of the city, the unremitting work of the intelligencestaff has been confined in times of peace. Every item of information has thus been systematically recorded ; and nothing concerning plague among the rats of Sydney 


\section{J. A. Thompson}

which can be learned in such ways, neither as to its presence nor as to its absence, remains hidden from us. But I would not draw an exaggerated picture. We had to learn this business ourselves, and we had to teach the public, without whose intelligent help much of what we know must have remained undiscovered; and therefore, although the above statement is quite correct, it should be noted that we improved both in accuracy and in completeness as experience accumulated, and our teaching spread.

The Director of the laboratories was Dr Frank Tidswell. I shall often have occasion to refer to his special work, when time permits; it sufficiently testifies to his industry, skill, learning and judgment, I believe, to those who have made acquaintance with it in the series of reports on this subject which has been published.

Invariably I use the word "identified" in relation to plague, to indicate discrimination of the disease by morphological, cultural, and inoculation methods, comparatively applied in all their respective details. Suspected plague whether in man or in animals was thus rigidly investigated whenever circumstances rendered certainty desirable (in first cases, for instance ; in all other animals than the ratmarsupials, whose susceptibility to this infection was first noted by Tidswell, 1902, p. 41 ; in "naturally-infected" guinea-pigs, because at our date of observation this event had been but once before recorded, and in a summary fashion; in all cats, dogs, etc.; and in all cases met with or suspected on board ship).

\section{Species of rats.}

It is convenient to speak of the rat in general, but $I$ wish to be understood to comprehend under that word three species and a variety. These are $M$. decumanus, the grey rat; $M$. rattus, the black rat, with its variety $M$. Alexandrinus rufus; and $M$. musculus, the grey mouse. We meet with all of them; all suffer from plague in nature in epizoötic form; and we have found all of them associated with plague in man.

$M$. decumanus is the grey rat; it lives in burrows, infests sewers, basements, and rights-of-way, and feeds on garbage. It can by itself cause plague in man, as we saw in the case of the troop-ship "Antillean" which carried no other species, and on which two cases of plague occurred in port, but before pratique had been granted (Sydney Report, no. 2, 1902, pars. 50-64). We have also found this species far from any town on the banks of a river 300 miles north of Sydney where, no doubt, specimens had been originally landed from Sydney cargo-boats. At the time of examination they extended to premises inland, where they were found in the village and on farms ; there, also, they alone were the cause of 12 cases of plague, of which 7 were fatal, and which occurred in 10 houses. Large numbers of rats were examined; there were but a half-dozen $M$. rattus among them, all of which were plague-free, while all the infected rats of which there were many were M. decumanus (Sydney Report, no. 4, 1905). This species cannot be tamed and in captivity soon dies as a rule.

$M$. rattus is the black, or ship rat; together with its variety $M$. Alexandrinus rufus, 
it prefers upper floors, roofs, sometimes the branches of climbing plants, and feeds on grain and fruits. This species is easily tamed, and lives but will not breed in captivity. We have found $M$. rattus alone in connection with plague in man; we have also found it in the same connection in conjunction with infected M. musculus only, and apart from M. decumanus. It, too, can by itself cause plague in man.

The opinion formed from our four years' continuous examination of rats is that at Sydney they breed all the year round, but probably a little less freely in the four colder months. At Brisbane, Q., which lies about five degrees further north, it is thought that they breed all the year round without variation.

Mice are less susceptible to experimental plague than are rats; from the following I infer that they may also be less susceptible in nature. During the epizoötic period 1st March to 3rd December, 1904, 20,394 rats were examined, and .99 per cent. were infected; by the same men during the same term 23,428 mice were collected on the same area, of which 26 were infected. However it must be remembered that these figures express only what happened to be found, and are incomplete. All the rats were not caught; still less were all the carcases discovered.

Rats eat each other in nature; rather more than 8 per cent. of the carcases brought in have been partly devoured, but sometimes so completely that nothing but the head, paws, tail and skin remained. We have also ascertained that rats eat mice in nature.

\section{Small proportion borne by infected rats identified to total rats examined.}

I take for convenience the $2 \frac{8}{4}$ years which ended on 31st December, 1904. During that term 125,872 rats and mice were examined in the laboratories. Out of this large total (which included none of those brought in by the public) plague was identified in but 37 per cent. On the other hand the meaning I attach to the word "identified " (see p. 549) must be borne in mind. A large number of putrid carcases came to sight, in which no doubt plague had been the cause of death though it could not be bacteriologically identified; yet if these could be reckoned as well the discovered deaths from plague would still compose but a small percentage of the total taken. Very many plague-rats die in their holes, where we have found some of them; the majority remain undiscovered.

4. Sick rats not often seen in the open.

With us the occasions on which sick rats have been reported to have come into the open could be counted on the fingers; they do not commonly discover themselves in the way so often seen in many 
countries. On the other hand, they do die in unusual places, and so regularly that we feel justified in regarding the discovery of three or four carcases at a similar stage of decomposition under floors, or in, or on the tops of cupboards, etc., during known presence of an epizoötic as probable evidence of death from plague. In ordinary, as is very well known, rats generally die out of sight; nuisance from them is uncommon. The contrary is the case when plague is epizoötic. Even when poison has been laid discovery of several dead bodies in such situations should arouse suspicion.

\section{Difficulties of rat-catching.}

Rats have to be searched out therefore; and to illustrate the difficulty of finding them I cannot do better than repeat the following statement. During a term of eight months the intelligence staff paid 17,656 visits to foreshores, wharves, and stores; only 4095 of those visits resulted in captures, and the number of rodents taken was only 10,579. These premises were entirely open to the men; but had the area examined been residential it is clear the result would have been still less satisfactory, since admission at night would often have been refused to them.

\section{Healthy rats most often caught.}

The means of catching necessarily selected, namely trapping, is obviously more likely to lead to the catching of healthy rats, active in their search for food, than sick rats, as I pointed out in 1902.

\section{Irregular infestation of buildings.}

We have found that all the buildings which seem to be likely to harbour rats are not infested with them. House to house examination of a group of blocks of squalid, but solidly constructed, buildings, which contained 387 houses, resulted in finding 57 infested with rats, or about 15 per cent. only, although all of them from dilapidation, and a majority from the uses to which they were put, appeared equally exposed to infestation. These blocks, then, furnished an explanation of the erratic incidence of plague on houses which has already been mentioned; not in that these 57 were infected, but in that they alone were infested. 
8. Small number of plague-rats usually found on single premises.

The number of plague-rats found on premises is usually small; that is to say from three or four to half-a-dozen. But occasionally, and for no obvious reason, the number has been large. I can mention 69,154 dead and 35 living, 72, 39 dead and 3 living, 80, 45, etc., found for the most part at produce stores under the floor of shops which had no basement; but these were quite exceptional numbers.

\section{Slow progress of the disease in hordes.}

With those few exceptions, also, the progress of the disease among the horde infesting any premises has been usually quite slow. This is an observation of so much importance that in $1903 \mathrm{I}$ published nine tables in illustration of it. Plague-rats and plague-mice were taken over quite long periods in conjunction with healthy rats and mice; and notwith-

Examples of slow progress of plague among hordes of rats.

Badly kept stabling for 100 horses, which stood on about 1500 square yards of blown sand, a long distance from the point of invasion.

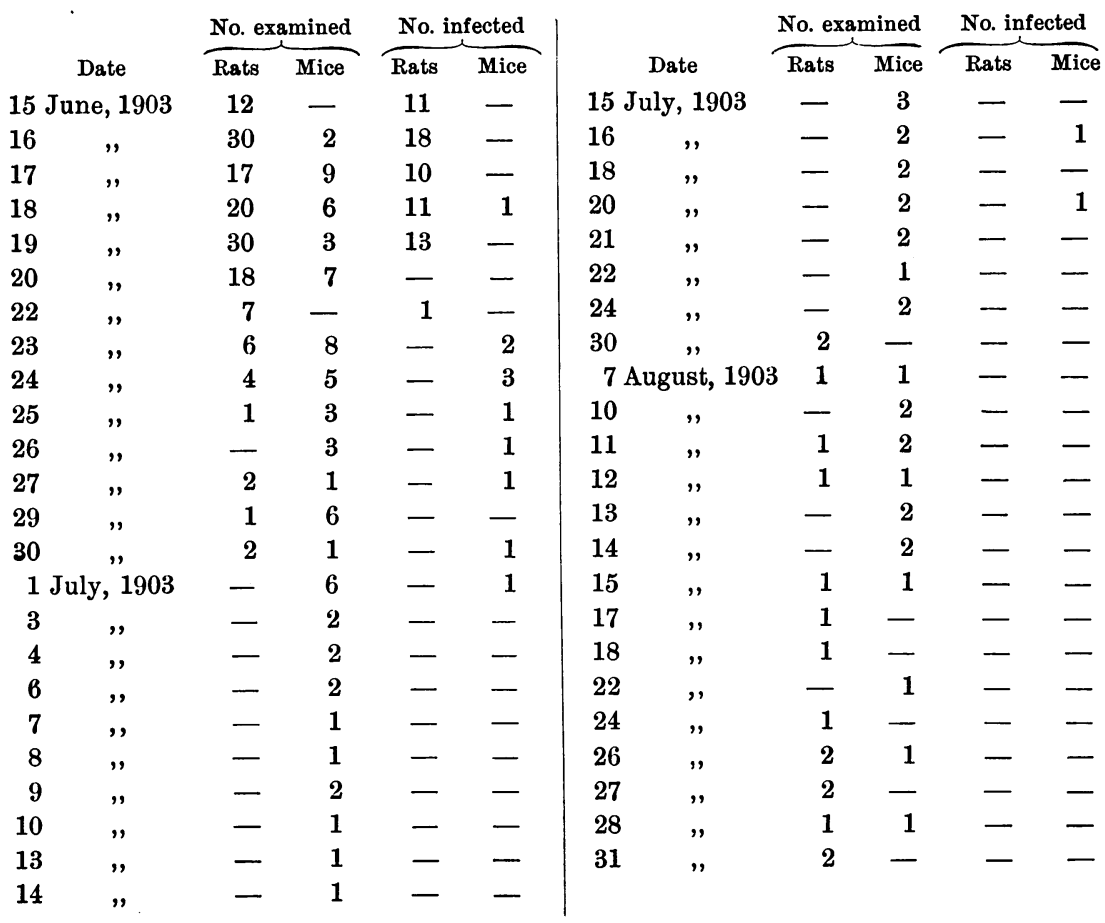


Produce Stores at the point of invasion.

\begin{tabular}{|c|c|c|c|c|c|c|c|c|c|c|c|}
\hline & & $\mathbf{A}$ & & & & & & B & & & \\
\hline & & No. exam & hined & No. is & ected & & & No. ex & nined & No. inf & ted \\
\hline & ate & Rats & Mice & Rats & Mice & & the & Rats & Mice & Rats & Mice \\
\hline 211 & 1903 & 1 & 2 & - & - & $16 \mathrm{I}$ & 1903 & 2 & - & - & - \\
\hline 21 & , & - & 1 & - & 1 & 19 & " & 2 & 1 & - & - \\
\hline 22 & ," & 1 cat & 1 cat & - & 1 & 22 & , & 2 & - & - & -- \\
\hline 22 & $"$ & 1 & - & - & - & 23 & $"$ & 1 & 5 & - & - \\
\hline 23 & ", & 1 & 4 & - & 1 & $12 J$ & e, 1903 & - & 3 & - & - \\
\hline 25 & ", & - & 3 & - & 2 & & 1903 & 1 & 1 & - & 1 \\
\hline 26 & , & 1 & 4 & - & 1 & 7 & ", & 1 & 2 & -- & 2 \\
\hline 26 & ", & - & 4 & - & 1 & 8 & ", & 1 & 18 & - & - \\
\hline 27 & ", & - & 3 & - & 2 & 9 & " & - & 2 & - & - \\
\hline
\end{tabular}

D

\begin{tabular}{|c|c|c|c|c|c|}
\hline \multirow{2}{*}{\multicolumn{2}{|c|}{ Date }} & \multicolumn{2}{|c|}{ No. examined } & \multicolumn{2}{|c|}{ No. infected } \\
\hline & & Rats & Mice & Rats & Mice \\
\hline \multicolumn{2}{|c|}{15 May, 1903} & 10 & 5 & - & - \\
\hline 18 & $"$ & 47 & 47 & - & - \\
\hline 19 & , & 1 & 1 & - & - \\
\hline 20 & , & 9 & - & - & - \\
\hline 25 & , & - & 1 & - & - \\
\hline 26 & ", & 1 & - & - & - \\
\hline 27 & ", & 1 & - & - & - \\
\hline \multicolumn{2}{|c|}{5 June, 1903} & 3 & 1 & - & - \\
\hline 6 & $"$ & 3 & 1 & - & - \\
\hline 9 & , & 2 & - & - & - \\
\hline 10 & , & 1 & 1 & 1 & - \\
\hline 11 & , & 1 & - & - & - \\
\hline 15 & $"$ & 16 & 7 & 3 & - \\
\hline 16 & $"$ & 8 & 5 & 7 & - \\
\hline 17 & $"$ & 12 & 5 & 2 & - \\
\hline 18 & $"$ & 5 & 3 & 2 & - \\
\hline 25 & " & - & 2 & - & 1 \\
\hline 29 & $"$ & 1 & - & - & - \\
\hline \multicolumn{2}{|c|}{1 July, 1903} & 1 & - & - & - \\
\hline 25 & 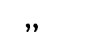 & - & 7 & - & - \\
\hline
\end{tabular}


standing disturbance the healthy animals continued to be caught long after the last infected animal had been taken. So that although, for some unknown reason, plague occasionally sweeps off the whole horde, it very much more often follows a slow course in buildings (as it did, also, on the troopship "Antillean" which was infected at Capetown, but arrived at Sydney 29 days later with some plague-rats and many more healthy rats on board her); and when it does so the horde does not become alarmed and does not flee the premises.

\section{Limit of the functions of the rat-search.}

These observations explain at once the long continuance of epizoötics, the small percentage of rats in which plague has been identified, the larger but still small percentage of rats reasonably presumed to have been killed by plague, the slow spread of the epizoötic, and the small number of separate premises at which presence of the disease in rats was established. Two practical conclusions to be drawn from them are these : First, a properly organised search can be made to reveal the limits of the area over which the epizoötic extends, but our best efforts will never tell us what the severity of the epizoötic was; secondly, discovery of a single plague-rat should be taken as the signal for strenuous exertion by the sanitary authority in that neighbourhood, and even in that quarter of the town. The percentages given above, it will be noticed, indicate merely what we succeeded in finding, not all that happened.

\section{The interval between epizoötics, and the "bridge" which connects them.}

The intervals between our epizoötics were in order, 15 months, $8 \frac{1}{2}$ months, $6 \frac{1}{2}$ months, and 45 days. Two causes have been assigned to recurrence and to persistence of rat-plague. One is possible saprophytic persistence of the bacillus, external that is to say, to the animal body; of that suggestion I believe I have disposed, as far as Sydney is concerned, by showing how easily areas are permanently rid of their infection. The other is that the rat is affected with plague in a chronic form, which causes but few deaths until something occurs to revive its virulence. I do not deny existence of a chronic form; but I say that while on the one hand we have failed to obtain any evidence which points to it, on the other hand we have found it an unnecessary hypothesis. Why had we intervals so widely different as one of 15 months and one of 45 days? 
As regards the former the obvious explanation of its length is that the disease had in reality been extinguished.

This, though unusual, is not unique ; Capetown furnishes a remarkable example of it. The first identified case occurred in February, 1901, the last, 2nd January, 1902 ; altogether 766 were recorded. The first identified plague-rat was taken on 4th February, 1901, the last, 19th January, 1902. No further plague case has since been recorded and, notwithstanding steady watch, no further plague-rat (but there was an outbreak of rat-plague at Lady Grey Bridge, a suburban railway-station outside Capetown in November, 1903, of which no explanation has been published). [See Cape of Good Hope Annual Reports of the Medical Officer of Health for the Colony, 1903.]

As regards the latter we may say without presumption that we know it was cut short by re-importation from another part of our own State. At all events while we had probably infected a northern river district (where an epizoötic began about the middle of December, 1904) by means of the numerous steamers which carry on the produce and dairying trades with it, the first plague-rats in 1905 at Sydney were caught at the very wharf at which those steamers lay to discharge. Secondly, as to the other two intervals of $8 \frac{1}{2}$ and of $6 \frac{1}{2}$ months; during them we can say (if our continuous and careful search throughout them availed anything) that we were certainly free from plague in rats; none of the 17,160 taken by the intelligence staff during the first, and of the 18,456 taken by it during the second, had plague. Thirdly, from the 18th of January, 1905 , to this date plague-rats have been found continuously; in very small number, and on the very short line of wharves already referred to, it is true, but they were all rats which had died of acute plague. These being the observed and, we believe, the completely observed facts, it seems to me that reference to chronic plague becomes superfluous; and as very little indeed has been ascertained regarding it, further reference to it may be deferred.

Such experience again is not exceptional. In accordance with what I said above, namely, that the need to watch rats as carefully as man had been generally overlooked, hardly any precise evidence on this point is forthcoming from other parts of the world. However, much the same thing seems to have been recently observed in Calcutta by Dr Frederick Pearse, (1904); and from returns regularly published by Dr John A. Gregory, Medical Officer of Health for Cape Colony, it appears that plague-rats in quite considerable number have been taken at Port Elizabeth in almost every week from 23rd August, 1902 (at all events) to January, 1906. As far as I have been able to make out the same may have happened at Hongkong; but as no one knows, nor ever has known, whether the plague-rats recorded there belonged to Hongkong or were imported for the sake of reward from neighbouring villages or the mainland, much stress cannot be laid on 
that (see Report of the Acting M. O. H. on Plague during the first seven months of 1903, p. 6, by Dr Wilfrid W. Pearse).

\section{Where plague-rats are most constantly found.}

Analysis shows that plague-rats have been found most persistently at wharves, then in warehouses and shops, then in stables, and then in more or less dilapidated cottages. One circumstance is common to all those kinds of places; either they are easily accessible to rats (cf. Hankin, 1898) or are used in ways likely to attract rats. Such uses are the storage and distribution of food-stuffs. But there is one use which is pre-eminently favourable to rat-infestation, and in connection with which we have most commonly found plague-rats; this is the producetrade in hay, straw, chaff in bags, maize, and potatoes. This point is well and importantly illustrated by our wharf-experience. I do not know what the total length of the wharf-line at which sea-going vessels lie may be, but it is many miles. Now, I have already said that our continuous examination of rats has been confined in time of peace to a wharf-line which measures only about four miles, and that we have learned that when plague recurs it will first show itself at a part of that line which is a little more than one mile long. But we can be still more exact, and assert with confidence that the chances are that the disease will reappear at some point within the half even of that mile; and that is precisely the part at which the produce-trade by sea with other States is carried on. So, also, all our sub-epidemics have begun either at retail produce-stores in the suburbs, or at stables to which produce has been carried in quantity from these wharves. If I were asked with what goods danger of the spread of plague is greatest I should have no hesitation in naming produce of all sorts, returned empties with packing still in them, and bundles of empty bags.

\section{Repeated infection of Sydney.}

In view of the evidence bearing on non-inherence of the infection in place of that touching the interval between epizoötics, and of that just mentioned which bears on association between plague-rats and a particular class of merchandise, I express with confidence the opinion that the successive epidemics at Sydney have been due not to continuous, but to repeated infection, which has always taken place by sea, and which has generally been connected with the importation of produce. Usually, though not always, the infection must have come to us from 
neighbouring States, and no doubt we have sometimes returned it to them. Plague has been maintained in Australia, I think, chiefly by an unseen, but traceable, interchange of the infection between ports; but occasional contributions from foreign countries have, no doubt, assisted from time to time, since its first introduction to the continent must have happened in that way.

\section{Mode of Infection.}

It is convenient at this point to consider very briefly the mode in which the infection is received by man.

\section{Inoculation.}

After pondering much that has been written on the pathology of plague, it appears to me that the evidence is greatly in favour of the view that its seat of election is the lymphatic system-a view which has been ably supported by Maximilian Herzog (1904), and that it is in favour, further, of the view that the commonest mode of receiving the infection is by inoculation through the skin. This, therefore, seems to me to be the mode of infection to which epidemic plague is due. Other modes are known to have been effective occasionally. Such for instance is drop-infection.

The suggestion that plague might be taken by the digestive tract seems to have been first made by Wilm in his preliminary report on plague (1896-1897). He based it on the signs observed at 30 out of 150 necropsies. They consisted in haemorrhages under the mucous epithelium of the stomach or intestines, swelling of the lymphatic follicles and of Peyer's patches, and sometimes ulceration of the latter. He remarked that general injection of the intestinal mucous membrane was usually present, but in some cases the alterations mentioned were so prominent that they seemed to him to indicate a primary infection of the intestinal tract. No better evidence for this mode of infection has been adduced by the few writers who, from time to time, have since espoused it on precisely the same grounds; its slender character, and its compatibility with origin in toxaemia, are apparent.

Wilm also supported his view by the successful results of his animal experiments, which he made by feeding either with cultivations or with the tissues of animals which had died of plague; in some of them the material was introduced into the stomach by means of a glass tube. These results, he said, meant more than those of inoculation experiments, because they approximated closely to natural conditions.

Simpson (1903) made an extensive series of experiments to show that a number of domestic animals, pigs, hens, calves, ducks, geese and sheep can be infected with plague by feeding with the organs of animals dead of the disease. He states that in the majority of instances he was able to convey the disease by feeding with 
comparative ease, and is inclined to think that alimentary infection is of importance in connection with human epidemics.

A repetition of Simpson's experiments in India by Bannerman (1904) and in Natal by Hill (1904) failed entirely to convey plague to any of the domestic animals.

But I would point out that a review of feeding experiments in general shows that success is more likely to attend on feeding with tissues than with cultures; and then, secondly, that such experiments by no means approximate to natural conditions, and at best could never be brought to explain epidemic plague. For the only source from which the food of man could receive the infection sufficiently often must be from the muzzles and mouths of rats, when it would be present in very small quantity, or from contact with their excreta when it must be in exceedingly small quantity (unless the dung itself were swallowed, which surely could rarely happen); and these conditions differ from the experimental conditions in the crucial respect of quantity of the virus taken, if in no other. But they do differ in another respect. It is that the virus administered in the cultures and in the tissues was actually growing, and at the highest pitch of its activity; while the virus casually communicated to food must be in a state of declining vitality, for in competition with true saprophytes $B$. pestis rapidly becomes overgrown. It is true that M. J. Rosenau's results (1901) which agree with those of Tidswell at Sydney (Sydney Report, no. 2, 1902, pars. 256-8) and of most other observers, show that the protected bacillus can persist outside the animal body during periods of time which vary with the conditions; but the judicious remark made by Passed Assistant Surgeon H. D. Geddings should be always borne in mind-namely, that the conditions which obtain in daily life are not on all-fours with those under which exact laboratory experiments are conducted. And I would enforce it by reference to a practical consideration. Our "normal" results have yielded many cases in which workmen were plainly infected at their workplaces. Now, these workmen carried their dinner with them in parcels in which it remained until dinner-time came round: and therefore, although their food was eaten in an infected place it may not be assumed that it was ever exposed to infection. That considerable body of people could not have been infected by feeding.

Wilm's excellent paper is so often referred to as though it were of equal value in all respects that it seems not unnecessary to point out here-though with all respect-that while no other trustworthy observer has ever succeeded in isolating the bacillus from human faeces (in which, nevertheless, it must often be present), he stated that his "culture examinations of faeces gave positive results in all of the fifteen cases examined, where well-marked enteric symptoms were present" (Sydney Report, no. 1, p. $3(e))$.

\section{The bacillus in the blood-stream.}

In accordance with that view is Tidswell's experience that the bacillus is rarely to be found in the peripheral blood-stream before the agonal stage of the disease, in which he agrees with the great majority of careful observers, among whom the Bombay plague committee (vide 
supra, The Bombay Plague 1900, p. 102), Calvert working at Manila (1900-1, 1903) and Powell working at Bombay (1904) may be specially mentioned. His method was to incubate the blood in the Widal pipette in which it had been collected for 24 hours before examining it.

\section{Mechanism of Inoculation.}

The means by which the bacillus comes to be inoculated into man has generally been assumed to be by contact between deposited infection and the skin; and it will be remembered that such contact was at first supposed by some to be the cause of preponderance of buboes of the inguinal region in people who habitually went barefoot.

Lowson (1897) had already pointed out in 1897 that the same preponderance was observed among soldiers on plague duty who wore boots (p. 13); and in 1900 we found that no less than 73 per cent. of the 286 fully clothed persons who exhibited buboes had them in the groin. This surmise has now been almost given up.

Tidswell (1903), p. 65, after having repeated the experiment of Albrecht and Gohn of the Austrian Plague Commission in India on inoculation by application of plague-cultures to the shaved skin of guinea-pigs, reached conclusions which warrant the following statement: (a) before infection can take place in that way there must be a breach of the epithelium, though not a bleeding wound; and $(b)$ that breach must be recent, for it becomes repaired in about 24 hours so that infection by that channel can no longer be effected. Those are two limitations which attach to man; but now let the other side of the matter be considered. First, in order to contribute effectively to cause epidemic plague in this way the infection must be deposited by the rat on objects with which man is likely to come into contact; but, secondly, on such objects it does not survive more than three, or perhaps, four days as a rule, and that only when it is protected from the competition for life of saprophytes to which, of course, it is exposed under the circumstances now contemplated. There then, already, are four conditions which must be fulfilled before infection through the skin can take place; and what is more they must be concurrently fulfilled within narrow limits of time. But there is yet another consideration of weight. It is that rats, after all, could thus infect only some few small spots, even in room; so that when the four conditions have been fulfilled within the requisite time, still the chances are greatly against accidental apposition between that small part of the body which has been injured, and those small spots in a room which have been infected. I believe it will not 
be thought necessary that more should be said in order to show that epidemic plague, though it be caused by inoculation, cannot be caused by accidental contact between the skin and deposited infection.

\section{Association of Epidemic and Epizoötic Plague.}

\section{There is a relationship in time and place between plague in rat and plague in man.}

The result of continuous examination of our rats has been to show us that rat-plague always coincides in place with plague in man, and in time always precedes it; but the presence of plague-rats was not always attended by plague in man. If, however, infection of the rat be a necessary condition of epidemic plague, a closer connection between plague-rat and man should be traceable. Accordingly, house-association between the two was often discovered. But often, on the one hand, it could not be discovered; and on the other, often when it was discovered it was not attended by cases in man. Further, the commonly accepted observation that actual contact with the plague-rat is unnecessary to infection of man, was corroborated, and as a matter of observation was learned to have occurred very rarely. Moreover, such contact when it had occurred, was generally not followed by infection; and that, it will be observed, was in accord with a very extensive laboratory experience which shows that the many persons who now habitually dissect plaguerats invariably escape infection, provided they do not wound themselves with their scissors and needles. The contradictory character of these several observations stands forth. The unavoidable inference from them is that if epizoötic plague is a condition precedent of epidemic plague, yet the plague-rat cannot be the only factor concerned. By itself the plague-rat is impotent. Nevertheless, I do not doubt that it is a necessary factor. Indeed, I see strong reason for regarding plague as a disease which belongs to, or primarily affects, the rat; for no ascertained fact has ever shown that it can originate with any other animal than the rat, nor that it ever prevails in truly epizoötic form among any other kind, save one. The exception is a species of marmot (Arctomys bobac), which is indigenous to Mongolia. This epizoötic was studied by Zabolotny (1899) but can have no direct bearing on our subject. 


\section{An interval elapses between the beginning of epizoötics and attack of man.}

Let us then survey the epidemic phenomena in hope of finding help in one of them towards solution of the puzzling problem which our normal results have disclosed. Out of many things which have been asserted of plague as the result of incomplete observation, occurrence of an interval between attack of the rat and attack of man stands out as a reality. We have seen it constantly; but we have also seen that it need not be long, as is generally asserted, but may be quite short.

The occurrence of a definite interval is well exemplified by the following observations. We have good reason for believing that our rats were dying of plague on the first occasion during the first week of January, 1900, and that they had probably become infected some time before; but the first case in man was not attacked till 19th January, the second not until 17th February ; and the disease did not become widespread till two or three weeks later still. In the second outbreak immediately after the first case had been notified we ascertained that the infection was already present at three or four separate points; namely at the produce-store at which the patient had been employed, at a wharf where produce was habitually handled, and soon afterwards at another produce-store, and at a stable a few hundred yards from it, all the latter having stood a little way inland of the wharf and all having probably been infected per saltum from it. Yet there was an interval of 34 days between that first case and the second, and of 35 days between the second and the third. In 1903 the epizoötic was recognised on 12th May.; but the first of the only two cases which followed was not attacked till 17th June. On the fourth occasion the epizoötic began 29th February at a certain produce-store ; the first person was attacked 9th March at that store whence he had removed dead rats as late as 3rd March, and where others were afterwards found and plague in them identified; but the second case did not follow until 32 days later. I need not continue the series, for I can say that an interval was observed on every occasion, both in districts and in houses.

\section{Evidence that rats must die before man can be attacked.}

Of this interval many mysterious things have been alleged; but I believe it is now hardly necessary to point out that the first step towards explanation of it lies in recognition of the simple requirement that time must elapse before the rats, which are usually first infected at such uninhabited places as wharves, etc., can sufficiently penetrate to the dwellings of man. But another condition contributes to lengthen it, which cannot be so easily explained. An interval is always observed even between the invasion of individual houses and the occurrence of cases in them. Now the difficulty of identifying plague in rats has already been mentioned. It has arisen in this, that however soon after 
attack cases have been notified, dead rats have been found, and usually they have been found in an advanced stage of putridity. Of this I could furnish very many specific instances. It is the common rule. Occasionally prompt notification has led to the discovery of fresh carcases; but always some of the rats found have died already. Plague-cases do not occur till rats have died of plague in the house, or in its immediate neighbourhood; then and not till then may man be attacked. We shall learn what $I$ believe to be the reason for this almost directly.

\section{Seasonal incidence of plague.}

With assistance of the first four outbreaks the seasonal incidence of plague at Sydney can be fixed. The first or crude statement is the following: The first epizoötic began with January, and the last plaguerat was identified in August; the second began in November, and the last plague-rat was identified in July; the third began in May and ended in August; the fourth began in March and ended at the beginning of December. But it requires some adjustment as to the beginning of the second and the end of the fourth outbreak. Although infection of the rats began in November, and evidence of it was found on four separate premises during the latter half of that month, no further evidence of it was got, notwithstanding continuous search, until the middle of January; in other words nothing that could be called an epizoötic then existed. The period of wide-spread plague in the rats did not set in until about the beginning of February. And as to the end of the fourth, although it actually fell in December, still the end of that which could be called an epizoötic prevalence clearly fell in September; the plague-rats identified during the three latter months of that year numbered only 5, 2 and 1 respectively. So that the epizoötic period may be fixed as falling between February and August, there or thereabouts. And the height of the epidemic period coincided nearly with the height of the epizoötic; March, April and May were the months in which the disease was most active in both forms-that is to say, in as far as we could estimate the smaller fluctuations of the latter.

I would here point out again that collection of plague-rats is never complete, nor nearly complete (unless on board empty ships), and that the numbers collected cannot be taken to indicate inferentially the proportional severity of the epizoötic. The rat-curves so frequently presented cannot be relied upon; they indicate the 
activity of the search perhaps, and may show its success; or they may only testify to the enterprise and cunning of natives who have brought rats in from outlying places for the sake of a reward.

\section{The Flea and Epidemic Plague.}

\section{Necessity for a living intermediary between man and rat.}

The results of "normal" observation which I have now described have explained nothing. They have served only to establish a series of contradictions. For instance, while it appears on the one hand that the infection is not diffused by fomites, on the other it has been credibly reported from other parts of the world where the conditions of life differed somewhat from ours that it has been seen to spread by that means, and not exceptionally. Again, while we have observed association between dead plague-rats and cases, we have seen reason in a small minority of instances for thinking that no plague-rats were present on premises which, nevertheless, had proved infective; more than that, it is quite clear that dead plague-rats are harmless to man. Then, when plague-rats have been ascertained to be present on inhabited premises, examination of the result has revealed similar contradiction. We have seen that persons who resort to such premises are liable to receive the infection; and yet that association has proved entirely harmless very often indeed. Again, although in that association multiple cases have sometimes occurred, by far the most often only one person has been attacked out of many exposed. I need not adduce more examples. The contradictory character of these and of other well-established events is striking; and it appears from them-a very important point-that the familiar crude observation of local coincidence between rat-plague and human-plague which is logically incompetent to establish causality as between rat and man, turns out to be quite incompetent in fact also as soon as it is examined by the epidemiological method. Indeed, when the crude coincidence is taken together with the contradictions the resultant evidence strongly suggests that both man and rat take plague, independently of each other, from some common source. So far, however, one consideration has been omitted which, in my opinion, has not received due recognition. This, broadly stated, is that the infection has been found external to man's body only in the bodies of the lower animals. Notwithstanding appearances, therefore, it must be that man receives the infection from the rat, although, as we know, the dead rat is certainly impotent to infect him. The crucial 
question, then, is how it comes to be communicated. Now, the intermediation of some insect which has the power of taking it from the rat and of inoculating it into man, and which can retain the latter power for a considerable, and perhaps for a rather long, time, is the only means consonant with all the recognised phenomena which can be imagined.

\section{Why the living intermediary must be the flea.}

By induction we had reached this stage in 1902. As soon as we had satisfied ourselves that an insect intermediary was necessary, we reviewed our notes to learn which insect was concerned if, perchance they might furnish a hint. I need not detain you with a long description of the search. We found 12 cases in the 1902 series-and more might have been found in the series of 1900 had the notes for that year been sufficiently full, since we found more after 1902-in which solitary buboes, situated in the femoral chain (resultant, therefore, from inoculation in the lower extremity) were exhibited by persons who had certainly received the infection at their workplaces. There they were all clothed. Their lower extremities were thoroughly well-protected, at all events from casual contact with deposited infection, by boots and socks or stockings, and by trousers or petticoats, while their hands, arms, and faces, and sometimes their chests too, no doubt, were fully exposed. Yet they were not inoculated in those exposed parts, but in their protected parts. These cases showed that inoculation must have been effected by some agent to which neither clothes nor the epithelium offered serious obstacles; by some agent which could evade the one, and which could penetrate the other without causing either noticeable

pain or a visible wound. It was perceived, of course, that the flea alone answered these requirements; and then that fleas, which commonly breed within houses in the dust in corners and in the cracks between flooring-boards, notoriously reach the legs first in places where they are numerous.

\section{What is the characteristic of the season of danger?}

We have seen already that the greatest prevalenee of epidemic plague has occurred with us during March, April, and May. The season of danger, which equally includes the time when it is most difficult to arrest epizoötic plague, may be fixed, then, as being the autumn, for with us midsummer falls in December, midwinter in June. That is the season when most people suffer, and when rats most suffer. 


\section{J. A. Thompson}

It is also the season of fleas. From about February onwards is the time when sandy patches, far removed from dwellings, begin to swarm with them; when domestic dogs are worried by the species which infests them as at no other time of year; and when one or other of the rooms in many a house which is neither dark nor dirty, but often of the better class, becomes for a time overrun with them. But although the months referred to are the time of special prevalence of fleas and of their more general obtrusiveness, it must not be forgotten that these insects are to be found all the year round, and in numbers in the warm, dark, places where they best breed.

\section{Summary history of the hypothesis of the flea.}

The more important points in the history of the flea-hypothesis are much as follows. Ogata (1897) communicated plague to mice by inoculating them with crushed fleas taken from infected rats. Simond (1898) formally espoused the hypothesis in a summary of his Indian experiences. He supported it by reference to epidemiological, clinical, and experimental observations, which did infinite credit to his acuteness and penetration in many respects ; but the epidemiological portion was (perhaps necessarily in his circumstances) unconvincing; his clinical observation of the frequent presence of reaction at the assumed point of inoculation in man has not been confirmed, although it was seen in four cases out of a very large number observed at Bombay (The Bombay Plague, etc., 1900, p. 104) and in one at Sydney (Sydney Report, 1900, p. 56); and his experimental evidence was seriously defective. Nevertheless his paper furnished ample ground for hopeful investigation on the lines indicated by him, and this we undertook with the results which have been described in our series of reports, and summarised in this paper. His experimental evidence consisted in successful repetition of Ogata's experiment, and in four experiments on the communication of plague from rat to rat by means of fleas. They resulted in infection with plague of one rat and one mouse. The species of the fleas used was not determined by him. Nuttall (1897 and 1898, Centralbl. f. Bakteriol. vols. xxII. 87 ; xxIII. 625 ) reported that several kinds of bacilli, among which plague was not included, soon lost their virulence in the flea's stomach, and he failed to communicate plague by means of bugs (Cimex lectularius). Galli-Valerio (1900) made some examination of the question which had been raised whether rat-fleas would bite man, and concluded that neither Typhlopsylla musculi nor P. fasciatus (Ceratophyllus fasciatus) would do so. He remarked that $C$ t. serraticeps was rarely found on the rat ; this our experiences in the same year (Sydney Report, No. 1, 1900, p. 40) did not contradict, and we now know it to be the case with our rats. Tiraboschi (1903) also carried out a long series of experiments with C. fasciatus, Ctenopsylla musculi, and some other less common species, and concluded that neither of them would bite man, but on the contrary showed positive distaste for his skin, although starving. Kolle (1901) made many attempts to communicate plague from rat to rat by this means without success. Tidswell (1903) communicated plague to a guinea-pig by injecting it with a crushed flea taken from a plague-infected rat, and 
discovered that $P$. pallidus was the common rat-flea in Australia ( $P$. cheopis, Roths.); this species has since been ascertained to be the common rat-flea in India. He found further that both that species and our $C$. fasciatus would bite man, if only they were starved. This latter experiment was carried out as in mosquito feeding; namely, the fleas were placed in test-tubes, the mouths of which were closed by fine gauze through which they bit. Gauthier and Raybaud (1903) made the same observation with C. fasciatus and (perhaps) with P. pallidus at Marseilles; and they succeeded in communicating plague from rat to rat by fleas in five instances (C. fasciatus). In the same year Galli-Valerio (1903) returned to the subject, reiterated his opinion that rat-fleas would not bite man, and adversely criticised Gauthier and Raybaud's work. About this time Captain Liston, M.B., I.M.S., working at the Plague Research Laboratory, Bombay, experimented on the transmission of plague by fleas; he used the method indicated above, by which the individual flea utilised was kept entirely under control, and had one success with $P$. pallidus among several failures. Liston (1905) suggested that the bacillus of plague must be transferred from rat to man as a condition of its continued existence; and Hankin (1906) described his dissection of the stomach of a flea which had been taken from the carcase of a plague-free rat found dead during progress of an epidemic of plague. From one half of the stomach he got a pure cultivation of $B$. pestis, as shown by involution-forms on salt-agar, etc. ; in the other half he observed bacilli with rounded ends which resembled $B$. pestis, in groups of about 12 each ; from which he inferred that they were growing there, and on their way to reach the salivary apparatus. These two latter suggestions do not seem very probable, for $B$. pestis is a schizomycete. Simond (1905) expressed his opinion that $C t$. serraticeps was for several reasons probably the species which most generally acted as agent; our observations have not supported that view, for as has been noted by us (Sydney Reports, 1900, 1903) it has been found on our rats but rarely.

\section{Fleas leave their proper hosts for other kinds of animals.}

It is well-known that different species of fleas have their proper hosts, and prefer them to other kinds of animals. Human-fleas do not infest rats, and rat-fleas do not infest man; were it otherwise the rule, perhaps, would be to find multiple cases in plague-houses instead, as is the case, of finding only one person infected out of several equally exposed to the danger. Why, then, should it be supposed that rat-fleas will leave the rat for man? Nuttall $(1899$, p. 21) and Liston (1905) made the suggestion that they remain with their proper host as long as it is available, and when it dies or is withdrawn, proceeds to seek food from the next nearest animal; and Liston supported it with some interesting observations. He mentioned two instances in which dogs and cats seemed to have saved their owners from attack by $C t$. serraticeps as long as they were present to afford food; but as soon as they had been withdrawn their 
owners were bitten. This accords with an observation of my own; namely, although pet dogs are tormented with fleas at the proper season, their mistresses in whose laps they lie are not (or very rarely are) attacked. But Liston was able to adduce further and more direct evidence. Rats having died of plague in a public garden at Bombay near a cage of guinea-pigs, presently the latter began to die of plague; and on searching the survivors he was able to collect from them a good many specimens of $P$. pallidus ( $P$. cheopis, Roths.) which in Bombay and in Australia is the common rat-flea, although guinea-pigs in India (and in Australia) seldom possess any fleas at all, and when they do so harbour only one or two specimens of Ct. serraticeps. He observed, also, transfer of the common rat-flea from rat to man. His attention was drawn to people who had been expelled from their house by the attacks of fleas. It appeared that on the 6 th or $7 \mathrm{tb}$ of a month the rats in the house had begun to die of plague; on the 11th fleas became so troublesome that the people had to sleep out on the veranda; on the 17th one of them fell ill with plague, and after him another; on the 20th Liston collected 30 fleas on the bodies of the remaining persons. As many as 14 of them were of the species $P$. pallidus. Yet among 246 fleas collected by him from the clothes of various persons under ordinary conditions but a single specimen of $P$. pallidus was found. May this indicate the reason of our observation that man takes plague only after rats have died of it?

\section{Power of any kind of flea to communicate plague not rigorously established as yet.}

Direct experimental proof of a satisfactory character that it is in the power of any species of tlea to communicate plague is at present wanting and it should be observed that after it shall have been given, still the epidemiologist alone can say whether the disease actually is commonly so spread. I do not doubt that the experimental proof will be forthcoming some day, and it occurs to me that I shall most usefully conclude by pointing out the reason for that confidence. It lies in this: We did not test the hypothesis of the flea because it had been put forward; we observed epidemic plague, and then found ourselves obliged to turn to it for an explanation of the phenomena (see Report, Sydney 1902, paragraph 299). Without it our "normal" results formed a heterogeneous collection of data which were either disconnected, or actually in conflict with each other; with it we found that those data fell easily into a concatenated series. Thus, to borrow from philosophical 
terminology, we arrived at a "theory of plague." That harmonious and complete reconciliation of all the observed phenomena certainly holds good at Sydney; and although the mode of diffusion of plague is likely enough to exhibit slight variations of detail under the different conditions which obtain in some other countries, in them also it must hold good in all essentials.

\section{REFERENCES.}

Bannerman, W. B. (1904), Report on experiments undertaken to discover whether the common domestic animals of India are affected by Plague. Report to Govt. of India. (Not published.)

Calvert, W. J. (1903), Plague bacilli in the blood. Centralbl. f. Bakteriol. Vol. xxxirr. Orig. p. 247.

Condon, J. K. (1900), Report on the Bombay Plague, 1896-99. Bombay.

Creighton (1905), Plague in India. Journ. of Society of Arts, vol. LiII. p. 813.

Galdi-VAlerio, B. (1900), Les puces des rats et des souris jouent elles un rôle important dans la transmission de la peste bubonique à l'homme. Centralbl. $f$. Bakteriol. Abt. 1., vol. xxvII. p. 1.

(1903), Les nouvelles recherches sur l'action des puces des rats et des souris dans la transmission de la peste bubonique. Centralbl.f. Bakt. Ref. vol. xxxiIr. p. 753.

Gauthier and Raybaud (1903), Recherches experimentales sur le rôle des parasites du rat dans la transmission de la peste. Revue d'hygiène, vol. xxv. p. 426.

Hankin, E. H. (1898), La propagation de la peste. Ann. de l'Inst. Pasteur, vol. xII. p. 705.

- (1905), On the epidemiology of Plague. Journ. of Hyg. vol. v. p. 79.

Herzog, M. (1904), The Plague, Bacteriology, Morbid Anatomy and HistoPathology. Bulletin of Bureau of Government Laboratories, Manila, no. 25483.

HiLl (1904), Report on Plague in Natal, 1902-1903.

Indian Plague Commission of 1898-9, Report of (1901), Par. 221.

Kolle, W. (1901), Berichte über die Thätigkeit in der zu Studien über Pest eingerichteten Station des Instituts für Infectionskrankheiten 1899-1900. Zeitschr. f. Hyg. u. Infektionskr. vol. xxxvi. p. 411.

Liston, W. G. (1904), Plague-rats and Fleas. Journ. Bombay Nat. Hist. Soc. Bombay. (1905), Indian Med. Gazette, p. 43.

Lowson, J. (1897), Report on the Bombay Plague epidemic. Bombay.

Ogata, M. (1897), Ueber die Pestepidemie in Formosa. Centralbl. f. Bakteriol. vol. Xxi. p. 774 .

Nuttall, G. H. F. (1897), Zur Aufklärung der Rolle welche Insekten bei der Verbreitung der Pest spielen. Centralbl. f. Bakteriol. vol. xxII. pp. 87-97. (1898), Zur Aufklärung der Rolle welche stechende Insekten dei der Verbreitung von Infektionskrankheiten spielen. Centralbl. $f$. Bakteriol. vol. xxIII. pp. $625-635$. 
Nuttall, G. H. F. (1899), On the rôle of insects etc. as carriers in the spread of bacterial and parasitic diseases of man and animals. Johns Hopkins Hospital Reports, vol. viII. $154 \mathrm{pp}$.

Pearse, T. F. (1905), Report on Plague in Calcutta for the year ending 30th June, 1904. Calcutta.

Rosenau, M. J. (1901), Viability of Bacillus pestis. Bull. no. 4 of the $U$. S. Marine Hospital Service. Washington.

Simond, P. L. (1898), La propagation de la Peste. Ann. de l'Inst. Pasteur, vol. xII, p. 625.

(1905), La question du véhicule de la peste. Rev. Médical du Brésil.

Simpson, W. J. (1903), Report on the causes and continuance of Plague at Hongkong, pp. 49-103. Hongkong.

Thompson, J. Ashburton (1900), Report on an Outbreak of Plague at Sydney, 1900.

- (1903), Report on a second Outbreak of Plague at Sydney, 1902.

(1904), Report on a third Outbreak of Plague at Sydney, 1903.

(1904), Report on a fourth Outbreak of Plague at Sydney, 1904.

Tidswell, F. (1903), Report on a second Outbreak of Plague at Sydney, 1902. By Ashburton Thompson.

Tiraboschi, G. (1903), Beiträge zur Kenntniss der Pestepidemiologie. Archiv f. Hygiene, vol. Xuvi. p. 251.

WILM (1896), Report on Plague in Hongkong, 1896. Hongkong.

- (1897), Ueber die Pestepidemie in Hongkong im Jahre 1896. Hygienische Rundschau, vol. vir. p. 217. 